\title{
EL CURSO DE MIRAFLORES EN TIEMPOS DE PANDEMIA: MEMORIAS DE LAS EDICIONES DE 2018 Y 2019
}

\author{
The Miraflores course in times of pandemic: \\ Memories of the 2018 and 2019 editions
}

\author{
PABLO GUERRERO VÁZQUEZ \\ Universidad de Zaragoza \\ pgv@unizar.es
}

Cómo citar/Citation

Guerrero Vázquez, P. (2020).

El curso de Miraflores en tiempos de pandemia: memorias de las ediciones de 2018 y 2019.

Revista de Estudios Políticos, 190, 323-340.

doi: https://doi.org/10.18042/cepc/rep.190.11

\section{Resumen}

El presente trabajo da cuenta de las dos últimas ediciones de un curso de verano celebrado desde hace doce ańos en Miraflores de la Sierra. Cada mes de septiembre, en este curso dirigido por los profesores Aragón y Solozabal, son estudiadas las principales novedades que afectan al Estado de las autonomías por académicos, políticos y profesionales de la justicia constitucional. En 2020, por razones sobradamente conocidas, el curso de Miraflores no se ha celebrado. Estas líneas han sido redactadas con la finalidad de mitigar la nostalgia que dicha suspensión provoca, aunque posiblemente ha conseguido justo lo contrario.

\section{Palabras clave}

Estado autonómico; reforma constitucional; Tribunal Constitucional; instituciones autonómicas, entidades locales.

\section{Abstract}

This paper summarizes the last two editions of a summer course held, for twelve years, in Miraflores de la Sierra. Every September, in this course directed by the 
professors Aragón and Solozabal, the main novelties that affect the State of the Autonomies are studied by academics, politicians and professionals of constitutional justice. In 2020, for well-known reasons, the Miraflores Course has not been held. This paper has been prepared with the purpose of mitigating the nostalgia that said suspension has caused, but has possibly achieved just the opposite.

\section{Keywords}

Autonomous State; constitutional reform; Constitutional Court; autonomous institutions; local entities. 
La nueva normalidad, posiblemente no es más que un oxímoron bajo el que ocultar una realidad mucho más descafeinada que la propia de la era pre-COVID. El verano de este año poco ha tenido que ver con el de 2019. Y, qué duda cabe, no es posible comparar el inicio del curso académico 2020/2021 con el anterior.

A caballo entre el final del verano y el inicio del curso, los profesores Aragón y Solozabal venían organizando desde hace varios septiembres, en Miraflores de la Sierra, un curso formidable sobre nuestra forma de Estado. Durante los últimos doce años este foro ha reunido en la sierra de Madrid a académicos de diferente procedencia para departir sobre los principales retos a los que se enfrenta el Estado de las autonomías. Lamentablemente, la decimotercera edición de este evento deberá esperar a septiembre de 2021, cuando las sesiones de mañana y tarde y las enriquecedoras tertulias informales entabladas durante los breves periodos de receso se puedan volver a celebrar con normalidad. Es decir, con pretérita normalidad. Para entonces, creo que nadie lo duda, el curso contará de nuevo con el apoyo de la Fundación Manuel Giménez Abad, que colabora habitualmente en su organización.

Estas líneas han sido redactadas una vez constatada la imposibilidad de celebrar una nueva edición del curso en 2020 , en parte con la finalidad de evitar la nostalgia que tal impedimento provoca. En lo que aquí sigue se dará cuenta de lo acaecido en ediciones anteriores y, muy especialmente, en las ediciones celebradas en septiembre de 2018 y 2019, de las que no se había dado cuenta. No obstante, debo adelantar que si bien la finalidad de este trabajo era eludir o mitigar la nostalgia, la redacción del mismo no ha hecho sino abundar en ella.

En 2018 el curso de Miraflores se celebró bajo el título «El sistema autonómico en transformación: problemática esencial». En 2019, la cabecera escogida para el mismo fue «El Estado autonómico ante una nueva oportunidad». En ambos casos, empero, el objetivo del curso fue, como en ediciones anteriores, realizar un seguimiento anual de la situación en la que se encuentra el Estado de las autonomías.

Esta finalidad se aprecia con mayor nitidez, si cabe, en la primera de las sesiones del curso, que se celebra tras la presentación del mismo por parte de sus directores. En ella, como conocen quienes hayan asistido algún septiembre a Miraflores, los ponentes analizan críticamente la jurisprudencia constitucional con repercusión territorial dictada en los últimos doce meses. No obstante, atendiendo a las excepcionales circunstancias, jurídicas y políticas, vividas en Cataluña entre octubre de 2017 y el verano de 2019, en las ediciones de 2018 y 2019 la primera de las sesiones del curso se dividió en dos bloques claramente diferenciados.

En primer lugar, en ambas ediciones, el profesor Aragón asumió el examen de aquellas controversias ordinarias, consustanciales a un Estado 
descentralizado. Ello llevó a Aragón Reyes a detenerse, por ejemplo, en el caso de 2018, en la STC 134/2017, de 16 de noviembre, que recoge algunas novedades en punto al poder del centro para determinar la densidad normativa de lo básico. O en la STC 7/2018, de 25 de enero, que resolvió un recurso de inconstitucionalidad interpuesto por más de cincuenta diputados del Grupo Parlamentario Popular contra determinados artículos del Código de Consumo de Cataluña. Sin entrar en el fondo de la controversia, sí que queremos dejar constancia de que el análisis de la STC 7/2018 puso de relieve algo evidente, pero que en ocasiones puede pasar desadvertido. A saber: que hay vida más allá del procés, pues no toda disputa jurisdiccional que ha enfrentado al centro con la Comunidad Autónoma de Cataluña durante estos años ha estado relacionada con la causa independentista. En esta misma línea, aunque ya en la edición de 2019, el profesor Aragón también hizo alusión entre otras a la STC 51/2019, de 11 de abril, que resolvió asimismo un recurso de inconstitucionalidad interpuesto por diputados del Grupo Parlamentario Popular, aunque en esta ocasión sobre la ley educativa catalana de 2009.

En todo caso, es honesto reconocer que las disputas más relevantes entre el centro y Cataluña se sustanciaron entre octubre de 2017 y el verano de 2019 al albur del proceso secesionista. Por ello, como se anticipaba, en la primera sesión del curso de Miraflores de 2018, y también en la de 2019, tras la intervención de Aragón Reyes, se reservó un espacio para analizar la jurisprudencia constitucional dictada en los meses precedentes en relación con el fatigoso procés. El repaso de tal jurisprudencia correspondió en 2018 a Josep Maria Castellà y Francesc de Carreras y en 2019 a Josu de Miguel; todos ellos conocedores de primera mano de la crisis constitucional que alcanzó su cénit en el otońo de 2017. La aprobación de Ley 19/2017, de 6 de septiembre, del Referéndum de Autodeterminación de Cataluña, y la 20/2017, de 8 de septiembre, de Transitoriedad Jurídica y Refundación de la República, constituyeron aparentemente un punto de inflexión en la realidad política catalana. Si bien, en septiembre de 2018 el profesor Castellà se encargó de recordar al auditorio que el escenario iniciado un año antes no constituía una nueva fase del procés, sino un agravamiento — cuantitativamente incuestionable- de la fase iniciada en 2015, en la que las instituciones catalanas se posicionaron, sin ambages, a favor de la desobediencia en el marco de un Estado de derecho.

No es este el lugar donde analizar de manera detallada el amplio elenco de resoluciones, autos y sentencias dictadas por el Tribunal Constitucional durante estos últimos meses sobre el procés. Entre ellas podemos destacar el ATC 126/2017, de 20 de septiembre, que contemplaba la imposición de multas de periodicidad diaria a los miembros de la Sindicatura Electoral de Cataluña, o las SSTC 114 y 124/2017, de 17 de octubre y 8 de noviembre, respectivamente, por las que se resuelven los recursos de inconstitucional 
interpuestos contra las antedichas leyes 19/2017 y 20/2017. También cabe mencionar la STC 89/2019, de 2 de julio, sobre la aplicación del art. 155 CE, e igualmente, la más indulgente desde el punto de vista de las instituciones catalanas STC 139/2017, de 29 de noviembre, en la que el Tribunal Constitucional resolvió la controversia sustanciada respecto a la reforma del art. 135 del Reglamento del Parlament, que regula la tramitación de las iniciativas legislativas por lectura única. Lo único que procede ahora es, por un lado, remitirnos a la monografía Justicia constitucional y secesión: el caso del proceso soberanista catalán, en la que el profesor De Miguel recapitula con brillantez y precisión quirúrgica la respuesta jurisdiccional al procés. Y por otro, limitarnos a apuntar que el TC, aunque continúa recordando que la CE es reformable por completo, ha comenzado a esgrimir, junto a argumentos de carácter competencial, cuestiones de principio para declarar la inconstitucionalidad de determinadas disposiciones normativas: soberanía nacional (art. 1.2 CE), principio de unidad (art. $2 \mathrm{CE}$ ) y sujeción de todos los poderes públicos, instituciones catalanas incluidas, a la Constitución (art. 9.1 CE).

El TC, sin separarse de la respuesta que desde otros Estados como Alemania o Italia se ha dado al fenómeno de la secesión, ha configurado a través de su reciente jurisprudencia el parámetro con el que deberán evaluarse los desafíos secesionistas que, desde Cataluña u otras partes del territorio, quieran plantearse al Estado constitucional en el futuro.

Estrechamente relacionado con ello, debemos hacer mención a la ponencia que también desde la mesa inaugural realizó Juan José Solozabal en 2018 sobre el proceso de reforma estatutaria que se había iniciado en el País Vasco. La intervención del profesor Solozabal daba continuidad a la ponencia que defendió justo un año antes en la anterior edición del curso de Miraflores. En septiembre de 2017 Solozabal sintetizó los caminos por los que podría discurrir una futura reforma del Estatuto vasco a la luz de los primeros trabajos realizados por la recién constituida Ponencia de Autogobierno. En septiembre de 2018, sin embargo, el ponente denunció que la propuesta de reforma, a pesar de ser sumamente inconcreta en aquellos aspectos no estrictamente orgánicos, caminaba ya decididamente por la senda confederal, resucitando aquellos aspectos más controvertidos del Plan Ibarretxe — como el Tribunal de Conflictos Euskadi-Estado- - Las ideas nodales de las bases aprobadas por la Ponencia eran la "nación foral» y el «derecho a decidir», un eufemismo con el que quiere hacerse referencia veladamente, tal y como ha quedado acreditado en Cataluña, al derecho de autodeterminación. Los redactores de las bases del proyecto de Estatuto para Euskadi realizaron, como denunció Solozabal, una lectura líquida, flexible y amigable de la Constitución, que no es conciliable con la jurisprudencia constitucional dictada en el marco del proceso secesionista catalán. 
Retomando el hilo de la coyuntura catalana, debe hacerse mención aparte a la repercusión que el procés ha tenido en la vida institucional de esta comunidad autónoma. Javier Matia, en la edición de 2018, hizo un repaso pormenorizado a la misma. Matia hizo especial hincapié en los problemas jurídicos que planteaba la investidura telemática de un candidato a la presidencia de la Generalitat de manera no presencial. Por entonces, Matia Portilla tan solo pudo hacer referencia al ATC 5/2018, de 27 de enero, en el que el Tribunal recordó que ni cabía la votación telemática del candidato ni cabía tampoco la votación presencial si no existía la pertinente autorización judicial (pues el candidato pretendido, el señor Puigdemont, se encontraba en rebeldía). No hubo ocasión, por ello, de analizar la STC 19/2019, de 12 de febrero, con la que se cerró tal procedimiento y que puso férreos límites al desarrollo de la virtualidad en la vida parlamentaria. La cuestión no es baladí, pues en febrero de 2019 pocos imaginaban que en poco más de un año sería imprescindible el desarrollo de sesiones parlamentarias no presenciales para evitar la paralización de la actividad institucional y del control gubernamental, no ya solo en Cataluña, sino en la totalidad de CC.AA. El estudio de las repercusiones que la COVID-19 ha tenido para la vida institucional de las CC.AA., y especialmente para sus Parlamentos, difícilmente podrá eludirse en la próxima edición del curso de Miraflores.

El grueso del curso de Miraflores, sin embargo, se dedica al estudio de las grandes cuestiones que giran en torno al desarrollo o al funcionamiento del Estado autonómico. Algunas de ellas, como la dimensión europea del modelo territorial, la posición de la Cámara Alta en nuestro sistema o el estudio de las entidades locales como una pieza más del esquema descentralizado español, son abordadas edición tras edición. Si bien, se analizan diferentes dimensiones de un mismo problema o se encomienda el estudio del mismo a un ponente diferente, que suele aportar al auditorio una perspectiva distinta.

Muestra de lo primero, a saber, del estudio de una dimensión diferente del mismo problema, fue el análisis del impacto que el proceso de integración europeo tiene en el proceso de descentralización español. En este sentido, en 2018 Ana Carmona y Antonio López Castillo se acercaron a esta cuestión desde una perspectiva fundamentalmente jurídica. Y analizaron, en este sentido y entre otras cuestiones, los mecanismos previstos para garantizar la participación de las CC.AA. en la determinación de la posición nacional en asuntos de la Unión (fase ascendente) o la posibilidad, remota en la práctica, pero plausible en el plano teórico, de activar el mecanismo previsto en el art. 7 TUE ante una aplicación desmesurada del art. $155 \mathrm{CE}$. Una decisión de este tenor, sin embargo, solo podría tener cabida en el caso de que al amparo del art. $155 \mathrm{CE}$ se aplicasen medidas contrarias a los valores fundamentales de la UE. Y no podemos olvidar que entre estos valores se encuentra el respeto al 
Estado de derecho, y que la reciente aplicación del art. 155 CE perseguía reparar los dańos provocados precisamente en este valor tras el embate dado al mismo por parte de las instituciones catalanas. Con ánimo polemista cabría apuntar que la aplicación del art. 7 TUE estaría más cerca de ser procedente en el caso de que el centro hubiese permanecido inane durante más tiempo ante la violación, constitucional y estatutaria, producida en Cataluña en el otońo de 2017.

En la edición de 2019 Antonio Cidoncha, Agustín Menéndez Menéndez y José Luis García Guerrero también abordaron la dimensión europea del Estado autonómico, pero centrándose en su vertiente económica: en el sustrato ordoliberal de la UE y sus repercusiones para la unidad de mercado, y en las consecuencias derivadas de la juridificación en el ordenamiento europeo del principio de estabilidad presupuestaria que ha restado, a priori, margen de actuación a los Estados, y muy especialmente a los entes subcentrales en los Estados descentralizados para desarrollar políticas sociales. En efecto, el equilibrio entre ingresos y gastos que proclama el principio de estabilidad se ha producido, fundamentalmente, ajustando a la baja los gastos en lugar de elevar los ingresos. Pero aun siendo ello cierto, queremos dejar constancia de que este comportamiento se ve favorecido por la falta de armonización fiscal. Tal y como teorizó Buchanan, una autonomía fiscal elevada en un contexto de descentralización política, en este caso de los Estados miembros de la UE, dificulta enormemente la elevación de los tipos impositivos y el mantenimiento de los servicios sociales por parte del nivel de poder encargado de prestarlos.

Una materia también recurrente en el curso de Miraflores es, como se adelantaba, la del régimen local. La inclusión de esta mesa, y su mantenimiento a lo largo de las diferentes ediciones, es un acierto que se debe resaltar, pues lo local no siempre ha sido estudiado con el detenimiento merecido por parte de la doctrina constitucionalista. La autonomía local es también autonomía política y, además, su naturaleza bifronte hace especialmente interesante su estudio desde el punto de vista de la distribución de competencias entre centro y periferia. En 2018, Antonio Cidoncha y Francisco Velasco fueron los encargados de abordar estas cuestiones. Velasco dedicó su intervención a desarrollar la propuesta de reforma de los artículos 140 y $141 \mathrm{CE}$, que junto con otros académicos había presentado unos meses antes a la FEMP y que pasaba, fundamentalmente, por deslindar con nitidez del título competencial en el que actualmente se fundamenta la normativa local del Estado (art. 149.1.18. ${ }^{\circ} \mathrm{CE}$ ), las cuestiones atenientes a órganos de gobierno de las EELL, competencias y financiación. En opinión de Velasco, estas cuestiones deberían ser desarrolladas en una ley orgánica que regularía, propiamente, un auténtico nivel de gobierno. Cidoncha, consciente de las dificultades políticas 
existentes para afrontar una reforma constitucional, señaló no sin pesadumbre que la defensa de la autonomía local debe continuar siendo asumida por el legislador básico estatal y por los legisladores sectoriales. Y para que llevasen a cabo tal función, el ponente apuntó algunas ideas motrices que deberían regir su proceder.

En 2019, en la mesa dedicada al régimen local, participaron Fernando Simón Yarza, Mónica Domínguez Martín, Enrique Guillén y Mayte Salvador Crespo, que recientemente había publicado El Gobierno local en España, en el marco de la colección Debates Constitucionales. Los temas abordados en esta edición del curso en materia local fueron de diversa índole. Podemos destacar, especialmente, la intervención de Enrique Guillén en punto a la posibilidad de "presidencializar» la forma de gobierno propia del ámbito local. En concreto, y aunque Guillén no eludió el estudio de sus principales debilidades, el ponente se decantó por un sistema en el que el primer candidato de la lista más votada fuese proclamado alcalde automáticamente. De esta forma, señaló el ponente, se evitarían novedosos modelos de alcaldía altamente disfuncionales, como las alcaldías rotatorias. También resulta interesante detenernos en la ponencia de Fernando Simón Yarza por aunar en su intervención dos temas a los que suele ser refractaria la doctrina constitucionalista: dentro de la esfera local, Simón abordó el estudio de su sistema de financiación. Fernando Simón se centró en el sistema impositivo diseñado para sustentar la autonomía local y, muy especialmente, hizo referencia a los problemas de constitucionalidad que había venido planteando la conocida coloquialmente como "plusvalía» (impuesto sobre el incremento de valor de los terrenos de naturaleza urbana). La STC 59/2017, de 11 de mayo, puso orden a este respecto. Aunque, como recordó el ponente, tan solo lo hizo parcialmente, pues en septiembre de 2019 todavía estaba pendiente de resolución una cuestión de inconstitucionalidad sustanciada en el marco de un proceso en el que la plusvalía real había sido inferior al valor catastral de la finca. Simón Yarza, no obstante, quiso dejar constancia de la buena salud financiera de la que disfrutaba el sector local en su conjunto, a pesar de que las fuentes tributarias que lo sustentan pequen, en ocasiones, de falta de racionalidad.

Especial atención merece, en todo caso, el debate sustanciado durante el turno de debate en punto a la necesidad de mantener la naturaleza bifronte del régimen local. Durante los últimos meses había adquirido un peso mediático notable el debate sobre el imparable proceso de despoblación de la España interior. En consecuencia, se evidenció que en España no existe una realidad local, sino múltiples; y que poco tiene que ver un municipio soriano o turolense con otro valenciano o andaluz. En este escenario, el establecimiento de un mínimo normativo común en materia local puede plantear problemas de funcionalidad. Por ejemplo, mientras en algunas partes del territorio las 
entidades supramunicipales son útiles asumiendo, a lo sumo, funciones de carácter asistencial, en otras más despobladas podría ser pertinente que asumiesen competencias sustantivas propias. El debate, en todo caso, tan solo quedó puesto encima de la mesa. Y, seguramente, habrá que esperar a 2021 para abordar con mayor detenimiento esta problemática.

En relación con la Cámara Alta, en 2018 fue Ignacio González García el encargado de abordar el estudio de esta cuestión. Y en 2019 esta encomienda recayó sobre Juan María Bilbao Ubillos. En una parte sustancial las ponencias de ambos fueron coincidentes, máxime porque ambos evitaron caer en los lugares comunes que han seducido a la doctrina en los últimos años. Como es sabido, hasta la fecha la doctrina venía denunciando que el Senado español no es una Cámara de representación territorial, ni por su composición ni por sus funciones. $Y$, en consecuencia, apuntaba a que la solución de buena parte de los problemas que aqueja nuestro Estado autonómico pasaba por su reforma, para convertir a esta institución en una verdadera Cámara de representación territorial. Directa o indirectamente, González y Bilbao pusieron de relieve que, a nivel comparado, no existen dos Senados iguales. Y González añadió que, prácticamente en todos Estados donde existe una segunda Cámara, esta está permanentemente cuestionada y son recurrentes los debates sobre su posible reforma.

Bilbao, en clave interna, abordó pormenorizadamente las distintas propuestas de reforma que han sido planteadas para reformar el Senado. Tanto aquellas de carácter reglamentario (a todas luces insuficientes, si se atiende a sus resultados, e incluso de dudosa constitucionalidad) como aquellas de carácter constitucional. En 2006, como recordó Bilbao, el Consejo de Estado realizó una propuesta de reforma constitucional que abordaba la problemática del Senado, pero que a pesar de ser aprobada en su día por unanimidad hoy dista de ser pacífica para la doctrina. Frente al modelo electivo propuesto por el Consejo de Estado, hoy son muchos los que continúan abogando por un Senado de composición gubernamental, de inspiración germana. A este respecto, Ignacio González, sin obviar que las relaciones intergubernamentales en España son débiles, denunció las dificultades teóricas que entrañaría atribuir funciones legislativas a un hipotético Senado con esta composición.

El seńuelo que tiene seducida a la doctrina desde hace un tiempo pasa por considerar que la representación territorial en el actual Estado de partidos continúa siendo posible. Sin embargo, Bilbao Ubillos se detuvo a desmontar este mito estrechamente relacionado con una concepción confederal de la representación. Llegados a este punto, y constatada también la esterilidad de una reforma que no contentará a unas fuerzas nacionalistas enrocadas en la bilateralidad, Bilbao destacó que las opciones pasaban por mantener la actual configuración constitucional del Senado o por suprimirlo. Ignacio González, 
que había llegado a una conclusión semejante en 2018, se decantó por la «no reforma». Bilbao, por el contrario, en 2019 consideró que el Senado era una institución prescindible, ya que se trata de una Cámara que nunca ha marcado la agenda política y su desaparición no alteraría nuestra forma de Gobierno.

Estrechamente relacionado con el papel del Senado en nuestro sistema institucional, Gonzalo Gabriel Carranza en 2019 estudió los diversos institutos que persiguen, sin lograrlo por completo, hacer efectivo el principio de colaboración intergubernamental. El ponente, que tomó la palabra tras Bilbao Ubillos, se focalizó en las relaciones de cooperación, poniendo de relieve que en España prevalecen aquellos instrumentos de carácter vertical (comisiones bilaterales), que benefician a las CC. AA. políticamente más fuertes, en detrimento de aquellos otros de carácter horizontal (conferencias sectoriales). En todo caso, Carranza evidenció que la cooperación, para ser realmente efectiva, requiere una mínima regulación, pero no un exceso de formalidad. De hecho, Bilbao Ubillos en la intervención anterior ya había puesto de manifiesto que no parecía aconsejable convertir al Senado en el centro de gravedad de la cooperación interterritorial por no poder una Cámara parlamentaria sustituir a los órganos intergubernamentales en cuanto instancia de diálogo y negociación.

En ambas ediciones del curso, por último, también se abordó el estudio de diversos aspectos relacionados con la forma de gobierno de las CC.AA. En la edición de 2018 Asunción De la Iglesia abordó, en materia de fuentes, el fenómeno de la legislación de urgencia y su empleo patológico durante los últimos años. Y, aunque la ponente evidenció que el recurso anómalo al decreto ley no es un rasgo característico propio de los ordenamientos autonómicos, pues el Estado también había recurrido a esta fuente con asiduidad últimamente, sí que quiso evidenciar que el empleo patológico de esta fuente es especialmente grave en el ámbito subcentral. En efecto, en sistemas con un Parlamento unicameral y mucho más reducidos en tamaño, es muy cuestionable que la tramitación legislativa por el procedimiento de urgencia no diese lugar a resultados potencialmente equivalentes desde el punto de vista del tiempo de tramitación. Pero, además, De la Iglesia recordó que actualmente no se ha articulado un cauce procedimental para que la minoría parlamentaria de las Asambleas Legislativas de las CC.AA. recurra ante la jurisdicción constitucional los decretos leyes dictados por el Ejecutivo autonómico.

Tras la intervención de Asunción de la Iglesia, tomó la palabra José Luis García Guerrero, quien centró su intervención en los problemas teóricos que se manifestaron tras la dimisión de dos presidentes autonómicos en el curso político 2017-2018: Pedro Antonio Sánchez, presidente de la Región de Murcia, y Cristina Cifuentes, presidenta de la Comunidad de Madrid. Como se recordará, ambos presentaron su dimisión en abril de 2018, en un momento 
en el que, por distintos motivos, su posición al frente de los Gobiernos autonómicos de Murcia y Madrid había quedado seriamente cuestionada y en el que, y esto es lo fundamental, había sido presentada contra ellos una moción de censura. García Guerrero criticó que ambos presidentes hubiesen podido presentar su dimisión con anterioridad a que se debatiera y votase la moción de censura que se había presentado contra ellos. Y trajo a colación el art.197.3 LRBRL, que en el ámbito local prohíbe al alcalde presentar su dimisión en el lapso temporal que transcurre entre la presentación de una moción de censura y su votación. El ponente recordó que la finalidad de la moción de censura no debe ser exclusivamente constatar la quiebra de la confianza parlamentaria establecida en el acto de investidura, sino también debe permitir sustanciar un debate sobre un programa alternativo de gobierno.

En mayo de 2019 se celebraron elecciones autonómicas en trece CC. AA., cuyos resultados vinieron a confirmar el cambio de ciclo político iniciado en 2015. Es cierto que, con anterioridad a tal fecha, algunas CC. AA. ya contaban con un sistema de partidos multipartidista, pero a partir de entonces, y más intensamente después de mayo de 2019, está tendencia se ha generalizado. Hasta el punto de que hoy en día lo excepcional es encontrar en el ámbito autonómico un Gobierno monocolor mayoritario. A propósito de esta coyuntura, Óscar Sánchez reflexionó sobre el equilibrio de poder entre los nuevos Gobiernos de las CC.AA. (monocolor minoritarios o de coalición) y sus Parlamentos. La intuición puede hacernos pensar que en un escenario de fragmentación política la institución parlamentaria se haya visto reforzada. Sin embargo, en su intervención Sánchez cuestionó precisamente esta hipótesis. El ponente puso de relieve que, aunque en este escenario existe una mayor dificultad para formar gobiernos en las CC.AA., una vez producida la investidura el mismo disfruta de gran estabilidad. Es cierto que en algunos extremos la institución parlamentaria se ha visto reforzada (revitalización de las comisiones de investigación, problemas para la convalidación de legislación de urgencia, incremento del número de iniciativas legislativas de origen parlamentario que triunfan - especialmente en casos de Gobierno monocolor en minoría-, etc.). Sin embargo, el ponente también puso de relieve un elemento fundamental que permite seguir observando vestigios de presidencialismo en la forma de gobierno de las CC.AA. En efecto, la influencia de la dirección de los partidos (y personalmente del líder) en la composición de la Cámara continúa debilitando la institución parlamentaria. Y, como es sabido, no ha sido presentada ninguna propuesta de reforma en el sistema electoral que permita enervar esta tendencia.

La profesora Yolanda Gómez abordó el tema de los procedimientos legislativos abreviados en los Parlamentos autonómicos. Para ello, la ponente partió de la premisa de que todas las Asambleas Legislativas autonómicas, en el uso 
de la autonomía reglamentaria que tienen reconocida estatutariamente, han previsto técnicas procedimentales tendentes a la agilización de la tramitación y aprobación de las leyes autonómicas, siguiendo para ello el diseńo trazado por los RCD y RS, si bien adaptándolo a la estructura unicameral de estas Cámaras autonómicas. En esta línea, la mayor parte de los reglamentos parlamentarios autonómicos han adoptado el modelo tripartito del RCD y RS, que constituyen el marco de referencia para la normativa parlamentaria autonómica. Así, han previsto tres procedimientos legislativos abreviados, con unas características y unos requisitos muy similares que los previstos por los RCD y RS, aunque en algunos aspectos existen divergencias importantes.

A tal efecto, se destacaron los rasgos de cada una de estas modalidades procedimentales $y$, en concreto, las singularidades que presentan los reglamentos parlamentarios autonómicos en relación con los reglamentos del Congreso y del Senado, y entre ellos entre sí. Asimismo, se apuntaron algunas de las cuestiones más controvertidas que han suscitado estas técnicas procedimentales en el ámbito autonómico. Con carácter previo se realizaron unas breves precisiones sobre los procedimientos legislativos abreviados en el modelo estatal. Así, se precisa que se utiliza la categoría «procedimiento legislativo abreviado" para referirse a lo que la doctrina ha denominado "procedimientos legislativos especiales por razón del tiempo de tramitación», es decir, el conjunto de técnicas procedimentales tendentes a la aceleración de los actos parlamentarios que integran el iter legis con la pretensión de agilizar la tramitación y aprobación legislativa. En nuestro derecho parlamentario se plasman, principalmente, en los siguientes métodos procedimentales: la delegación de competencia legislativa plena en las comisiones parlamentarias, la variante del procedimiento de lectura única y el de urgencia.

La edición de 2019 también contó con la intervención de Andrés Dueñas Castrillo, quien abordó los instrumentos de participación directa desarrollados a nivel autonómico. El ponente se mostró favorable a su regulación, aunque denunció que el debate sobre este tipo de instrumentos había quedado desenfocado por el proceso secesionista vivido en Cataluña en los últimos años. En este sentido, Dueñas Castrillo remarcó que, más allá de los referéndums o las consultas populares, existen otros instrumentos de democracia directa que pueden constituir un complemento necesario a nuestra democracia representativa. En este sentido, Dueńas acercó al auditorio a los diferentes instrumentos participativos introducidos en los Parlamentos autonómicos durante la legislatura 2015-19 a través de diversas reformas reglamentarias. Estas novedades, anticipó el ponente, han innovado las dos funciones parlamentarias clásicas: la legislativa y el control. En relación con lo primero, el ponente destacó la posibilidad de que los ciudadanos introdujesen enmiendas durante la tramitación parlamentaria de iniciativas legislativas, 
aunque en todos los casos que ha sido prevista esta modalidad la enmienda de origen ciudadano debe ser asumida en un breve periodo de tiempo por un grupo parlamentario. En punto a los instrumentos de control o impulso, Dueñas Castrillo se refirió a las proposiciones no de ley de iniciativa popular y a las preguntas ciudadanas. El ponente concluyó apuntando que, si bien estos instrumentos cuentan todavía con una corta experiencia, en caso de resultar exitosos en el ámbito autonómico cabría pensar en trasladarlos al estatal.

Por último, vamos a dejar constancia de otras cuestiones que fueron abordadas en alguna de las dos ediciones de las que se da cuenta en esta crónica. En 2018, la presencia en Miraflores del secretario de Estado de Política Territorial, Ignacio Sánchez Amor, permitió pasar por unos minutos de las musas de la academia al teatro de la política. Su intervención fuera de programa aportó una perspectiva práctica de algunos de los principales retos de nuestro Estado de las autonomías. El secretario de Estado hizo especial hincapié en las relaciones entre el Estado y las CC.AA., caracterizadas, por un lado, por la desconfianza por parte del Estado hacia las CC.AA., y por otro, por la irresponsabilidad de algunas CC.AA. que en situaciones críticas han optado por trasladar sus problemas al centro. Para superar esta situación, Sánchez Amor consideró necesario perfeccionar los mecanismos de cooperación con los que ya cuenta el Estado autonómico, sin que para ello sea necesario reformar la Constitución. De hecho, el ponente consideró que no existía una ventana de oportunidad política que permitiese acometer entonces (posiblemente tampoco hoy en día) una reforma constitucional.

Dentro del marco constitucional actual, Sánchez Amor distinguió entre aquellas mejoras de las relaciones de cooperación entre el Estado y las CC. AA. que eran deseables — como la mejora del funcionamiento de la CARUE—, y aquellas de carácter debido. Entre estas últimas, el ponente se refirió muy especialmente al tradicional incumplimiento por parte del Estado de la jurisprudencia constitucional dictada en materia de subvenciones. $Y$ anunció que aquella misma mañana el Consejo de Ministros iba a aprobar un real decreto que facilitaba la participación autonómica en el reparto de unas subvenciones para implantar instalaciones de refrigeración (a la postre, Real Decreto 1114/2018, de 7 de septiembre). Por otro lado, a la hora de perfeccionar las relaciones de cooperación, Sánchez Amor quiso evidenciar que la bilateralidad podía ser un instrumento útil, siempre que en este tipo de relaciones se abordasen exclusivamente aquellos problemas relacionados estrechamente con las singularidades específicas de una comunidad autónoma.

Tras la intervención del secretario de Estado tomó la palabra Josu de Miguel, quien abordó las cláusulas constitucionales de integración territorial. De Miguel recordó que en ocasiones, al analizar las principales disfunciones 
del Estado autonómico, se llega a la conclusión de que las mismas son debidas a una falta de cultura federal. Y se esgrime que la falta de dicha cultura ha sido provocada, o al menos favorecida, por un marco constitucional parco en cláusulas de integración. El ponente, sin embargo, negó de plano esta posibilidad y afirmó que la Constitución de 1978 es integradora, sobre todo en perspectiva comparada. Al igual que lo era la Constitución republicana de 1931, que configuró un Estado integral, a medio camino entre el centralismo y el federalismo, que siguiendo las tesis de Azaña y en contraposición a las de Ortega perseguía integrar el sentimiento de Cataluña dentro de una Constitución racional normativa. El art. $2 \mathrm{CE}$ positiviza indirectamente el concepto «nación de naciones», en lugar de reafirmar el de «nación de ciudadanos», que es el que por lógica debería deducirse del principio de soberanía popular que proclama el art. 1.2 CE. El art. $3 \mathrm{CE}$, al reconocer la cooficialidad de otras lenguas, constituye otra cláusula de integración. Y también el art. $4 \mathrm{CE}$, una disposición constitucional que no tiene parangón a nivel comparado, y que sitúa al mismo nivel normativo la bandera española y las autonómicas.

La Constitución de 1978, denunció De Miguel, mira al futuro en algunos extremos - fundamentalmente en materia socioeconómica一, pero se abre a un tiempo premoderno en materia territorial, a través de la DT-2 y, fundamentalmente, de la DA-1. El nacionalismo vasco, aunque también recientemente el aragonés ${ }^{1}$, han leído la apertura de la Constitución al fenómeno foral como una cláusula que permite la integración en el Estado sin que ello comporte, necesariamente, la integración en el propio orden constitucional. Llegados a este punto, De Miguel se preguntó retóricamente si no habría sido más conveniente que la Constitución hubiese sido más prudente a la hora de reconocer cláusulas de integración, pues en buena medida han provocado un efecto diametralmente opuesto al esperado. El ponente, además, recordó que en la última ocasión en la que el CIS preguntó a los españoles sobre la Constitución, en 2008, solo para un $4 \%$ su principal valor era que permitió organizar la autonomía, frente a un $43 \%$ para el que la Constitución era valiosa por ser un instrumento que garantizaba la libertad. $\mathrm{Y}$, en relación con ello, De Miguel concluyó su intervención señalando que los ciudadanos, cuando se les pregunta, pueden dar grandes lecciones de derecho constitucional.

También en la edición de 2018 intervinieron en una misma mesa Tomás de la Quadra-Salcedo Janini y Eva Sáenz Royo para abordar dos temas

1 Ley 8/2018, de 28 de junio, de actualización de los derechos históricos de Aragón, cuya inconstitucionalidad fue declarada parcialmente por STC 158/2019, de 12 de diciembre. 
íntimamente relacionados entre sí: el modelo de distribución de competencias y el sistema de financiación diseñado para que los entes subcentrales puedan ejercitar las mismas. La mesa resultó muy sugerente, porque quizás hasta la fecha no han sido analizada con la serenidad que debería las relaciones existentes entre el diseńo del sistema de distribución de competencias (prevalencia o reparto) y el de financiación (separación o unión).

De la Quadra-Salcedo especialmente centró su atención en el sistema de bases-desarrollo, que consideró digno de conservar. Y con nitidez quiso diferenciar este sistema de los títulos competenciales de carácter horizontal (arts. 149.1. $1 .^{\circ}$ y $13 .^{\circ}$ ), que permiten al Estado intervenir en determinadas materias sobre las que las CC.AA. también proyectan su ámbito decisorio, pero a través de un título competencial más concreto. El ponente recordó que la definición de las bases no se realiza en la Constitución, sino por el Estado, a través de normas de rango infraconstitucional. De modo que la determinación del mínimo normativo común - es decir, del equilibrio entre unidad y autonomía - depende de la voluntad del Estado, que está sujeto en todo caso a los límites formales y materiales determinados por el Tribunal Constitucional. El ponente, no obstante, reconoció que el control de estos límites no es una tarea sencilla para el TC y valoró positivamente que el Senado tuviese un papel más activo en la definición de las bases. En cualquier caso, el ponente quiso dejar constancia de que, en su opinión, el límite a la capacidad de las CC.AA. para mejorar el mínimo común establecido por el Estado no está en el alcance de las competencias estatales, sino en la obligatoriedad de observar el principio de estabilidad presupuestaria.

Sáenz Royo comenzó denunciando que los juristas, y en concreto los constitucionalistas, han contribuido de manera muy discreta a diseñar el actual sistema de financiación autonómica. Y ello ha provocado que este haya sido desarrollado, en buena medida, de espaladas al sistema de distribución de competencias diseñado por la Constitución y los estatutos de autonomía. Para la ponente, en el futuro habría que garantizar que aquellas materias en las que se atribuye al Estado la competencia legislativa, lo previsto en la normativa estatal sea sufragado con cargo a los presupuestos generales del Estado. Y ello con independencia de que el Estado sea competente a través del sistema de bases - en materia sanitaria (art. 149.1.16. ${ }^{\circ} \mathrm{CE}$ ) o educativa (art. 149.1.30. CE) - o con fundamento en un título competencial horizontal - por ejemplo, en punto al desarrollo del sistema de dependencia (art. 149.1.1. ${ }^{\circ}$ CE) - . Si bien, la ponente no cerró la puerta a que la gestión de estos recursos fuese realizada de manera desconcentrada por las CC.AA., para lo que previamente debería calcularse cuál es el coste por habitante ajustado de la prestación de estos servicios en las diferentes partes del territorio. En aquellas materias en las que la decisión legislativa correspondiese a las CC.AA., Sáenz 
Royo abogó por que fuesen financiadas con recursos propios de las CC.AA., obtenidos mediante el ejercicio por parte de los entes subcentrales de su capacidad tributaria. Es decir, planteó un escenario en el cual, partiéndose de una situación simétrica de iure entre todas CC. AA., cupiese llegar a una situación de asimetría de facto, en tanto que algunas regiones prefiriesen no ejercitar su potestad tributaria y, en consecuencia, contarían con un ámbito de decisión política más reducido. Para subsanar los problemas que para el principio de igualdad podría provocar este modelo, Eva Sáenz abogó por reconsiderar el papel que está llamado a desempeñar en nuestro sistema el fondo de compensación inerterritorial (art. 158.2 CE). En último lugar, Sáenz Royo abordó la asimetría, en este caso perversa, que provoca el concierto vasco - y su cupoy el convenio navarro - y su aportación-. Estos instrumentos transmutan en esta parte del territorio nacional el principio de autonomía financiera por otro de soberanía financiera, con notables problemas para el principio de solidaridad. Un escenario pernicioso que, en opinión de la ponente, se debería superar.

En relación con la edición de 2018, a la última intervención a la que queremos hacer referencia es a la impartida por el profesor Aguado Renedo sobre la problemática secesionista en Canadá. César Aguado trajo a colación algunos titulares de prensa publicados en abril de 2018, de los que se deducía que, según una reciente sentencia de la Corte Suprema de Quebec, bastaría con la mitad más uno de los votos emitidos en un referéndum sobre la independencia de la provincia francófona para escindir ese territorio del resto de Canadá. Los titulares periodísticos eran sorprendentes, máxime cuando la Ley de Claridad ${ }^{2}$, dictada en 1999, estipuló que para que el Gobierno de Canadá negociase con el Gobierno de Quebec sobre una posible independencia de esta provincia era imprescindible que los quebequeses hubiesen expresado con claridad su voluntad de separarse, y que sería la Cámara de los Comunes, en todo caso, la encargada de interpretar si dicha mayoría era o no suficiente como para iniciar esas conversaciones. Aguado Renedo, para situar el debate en sus justos términos, sintetizó los principales hitos del proceso independentista quebequés y recordó que tras el ajustado resultado del referéndum de autodeterminación de 1995, a) el Gobierno federal consultó a la Corte Suprema de Canadá si cabía la secesión unilateral por parte de Quebec; b) la Corte Suprema canadiense estipuló en 1998 que para que los Gobiernos federal y quebequés iniciasen negociaciones de buena fe, la pregunta sobre la secesión de Quebec debía ser clara y la opción a favor de la secesión debía ser

2 Loi donnant effet à l'exigence de clarté formulée par la Cour suprême du Canada dans son avis sur le Renvoi sur la sécession du Québec, de 29 de junio de 2000. 
apoyada de manera mayoritaria por los ciudadanos; c) el Gobierno federal aprobó la Ley de Claridad, en la que desarrolló los requisitos establecidos por la Corte Suprema, y en la que reservó al Parlamento nacional la determinación de la mayoría suficiente para iniciar dichas negociaciones — que seguía sin concretar-, y d) Quebec, en respuesta a la Ley de Claridad, dicto la Ley $99^{3}$, en la que se establecía que dicha mayoría debía ser del $50 \%$ más uno de los votos emitidos en un referéndum. La Corte Suprema de Quebec en 2018 avaló la constitucionalidad de la Ley 99 en un pronunciamiento doctrinalmente muy sólido, ya que ante la ausencia de una norma constitucional que defienda la autonomía de Quebec, esta decisión ha sido vista como una oportunidad para defender el espacio constitucional de la provincia.

Pero la sentencia reitera que la mayoría a la que se refiere la Ley 99 no es la necesaria para declarar unilateralmente la independencia de Quebec, sino para iniciar negociaciones de buena fe con el Gobierno federal. Y, de todos modos, la última palabra en este proceso la tendrá la Corte Suprema de Canadá, que en opinión de Aguado cuenta con argumentos a favor para considerar que la mayoría simple no es un criterio admisible para tomar decisiones sobre cuestiones trascendentales para el cuerpo político. En efecto, como recordó el ponente, Canadá es el único sistema parlamentario de toda América, y en estos sistemas no es extraño la exigencia de mayorías reforzadas. En 2017, en la anterior edición del curso de Miraflores, Aguado ya se había posicionado a favor de que en referéndums de carácter plebiscitario se exigiese una mayoría cualificada para que los resultados de estos pudiesen tener carácter vinculante. Las aciagas consecuencias provocadas por los plebiscitos sobre el brexit o el acuerdo de paz colombiano, resueltos vinculantemente por una mayoría muy ajustada, daban la razón al ponente.

La edición de 2019 albergó una sesión de trabajo del proyecto de investigación «El control de la ley: constitucional, comunitario y convencional» (DER2016-78391-P)», dirigido por los profesores Aguado Renedo y López Castillo. En la misma se abordó una cuestión estrechamente relacionada con la temática del curso. A saber, el control de constitucionalidad de las leyes subcentrales en España (Ignacio González), Italia (Alberto Macho) y Alemania (Antonio Arroyo), y también, de los estatutos de autonomía de las CC. AA. (Tomás de la Quadra-Salcedo), de los estatutos de las regiones italianas (Pablo Guerrero) y de las constituciones de los Länder alemanes.

La clausura del curso corre a cargo, en ausencia de Rubio, del profesor Aragón. Tras unas breves palabras de cariño dirigidas cada año al maestro,

3 Loi sur l'exercice des droits fondamentaux et des prérogatives du peuple québécois et de l'État du Québec, de 13 de diciembre de 2000. 
Aragón Reyes sintetiza lo debatido en las sesiones anteriores y realiza una valoración global del Estado de las autonomías. Visto con perspectiva, cabría afirmar que en la edición de 2018 la gravedad de la crisis territorial toco fondo, mientras que en 2019 cupo apreciar una leve recuperación. Manuel Aragón suele reservar sus últimas palabras, en primer lugar, para animar a la academia a no cejar en el estudio de una problemática, la territorial, que puede empezar a parecer irresoluble, pero cuya superación resulta ineludible. A continuación, y para concluir, emplaza a cuantos allí se encuentran a asistir el próximo septiembre a otra edición de este observatorio anual del Estado de las autonomías. Frustrada por causa de fuerza mayor la edición de 2020, solo se puede poner el punto y final a esta crónica deseando que la última invitación del profesor Aragón se haga extensible a la edición de 2021. 